\title{
INCIDENCE OF DYSPHAGIA AFTER SINGLE LEVELANTERIOR CERVICAL DISCECTOMY WITH PROSTHESIS VERSUS BLADE CAGE IMPLANTATION: A RETROSPECTIVE STUDY
}

\author{
• Önder Çerezci \\ Üsküdar University Faculty of Health Sciences, Department of Physiotherapy and Rehabilitation, Istanbul, Turkey
}

Objective: This study compared complaint of dysphagia in patients that underwent bladed peek cage or prosthesis implantation following single level anterior cervical discectomy.To understand that is there any risk factors of dysphagia after anterior cervical spinal surgery

Materials and Methods: Ethical approval was obtained from Üsküdar University Chair of Non-Interventional Studies Ethnics Committee with no: 61351342/AGUST 2021-01. Fourty patients who underwent bladed peek cage or prosthesis implantation after single level anterior cervical discectomy in our clinic in 2019 were enrolled in our study. Group A included 10 male and 10 female patients who underwent bladed peek cage implantation after single level anterior cervical discectomy, while group B included 10 male and 10 female patients who underwent prosthesis implantation after the same procedure.

Results: Both groups were evaluated in early postoperative period, first postoperative month and third postoperative month. There was no significant change in frequency of dysphagia between both groups in the early postoperative period, first postoperative month and third postoperative month. There were 5 female and 3 male patients (total: 8) with dysphagia in group A in the early postoperative period. Group B included 4 female and 3 male patients (total: 7) with dysphagia in the early postoperative period.

Conclusion: No difference was identified in terms of dysphagia between patient groups that underwent bladed peek cage or prosthesis implantation after single level anterior discectomy. Dysphagia complaint in both groups detected in the early postoperative period totally resolved by the end of third postoperative month.

Keywords: Anterior cervical discectomy, bladed peek cage, prosthesis, dysphagia

\section{INTRODUCTION}

Several risk factors have been reported regarding development of dysphagia after anterior cervical spinal surgery; however, almost all of them are controversial ${ }^{(1)}$.

The results of a meta-analysis study indicated that anterior cervical plate use, multiple surgical levels, upper cervical spinal surgery and rhBMP-2 use in women are risk factors for development of dysphagia after anterior cervical spinal surgery. Normal swallowing function involves more than 30 muscles, which can be performed up to 600 times daily. Dysphagia may occur at any stage of swallowing. These are oral preparation and transport stage, which includes sucking, chewing and transport of liquid or solid foods; pharyngeal phase, including initiation of swallowing reflex, transport of foods downwards, closure of airway to prevent suffacation or aspiration of food, and the esopgaheal phase composed of loosening and contraction of the openings in upper and lower sections of esophagus in order to transport food to stomach ${ }^{(2,3)}$.
Being aware of the patients with dysphagia in our rehabilittaion programs, we followed-up patients, who underwent single level discectomy surgery, for 3 months and aimed to observe how the surgery, materials used in surgery and different peroperative methods reflected in the outcome.

\section{MATERIALS AND METHODS}

Ethical approval was obtained from Üsküdar University Chair of Non-Interventional Studies Ethics Committee with no: 61351342/AUGUST 2021-01.

Retrospective questioning of the 40 patients (20 male, 20 female), who underwent single cervical disc hernia surgery followed by bladed peek cage or prosthesis placement as a part of anterior discectomy, in the year 2019 in our spine center. Patients were divided into 2 groups. Group A included 10 male and 10 female patients with bladed peek cage implantation after single level anterior cervical discectomy, while group $B$ included 10 male and 10 female patients who underwent 
prosthesis implantation after the same procedure. Dysphagia was questioned by an independent investigator by asking the patient 5 questions on the first postoperative day. Dysphagia was categorized into 4 degrees by weighting (Bazaz Yoo dysphagia severity scale). The same test was repeated with an independent investigator in the first and third postoperative months. Results were collected and analyzed by using IBM SPSS Statistics Version 25. Normality analysis were performed by using Kolmogorov-Smirnov test, Shapiro-Wilk test, Histogram and Variance coefficient. Related groups were compared by using Wilcoxon test. $\mathrm{P}<0.05$ was considered significant (Table 1) $(4,5)$.

\section{RESULTS}

Both groups were evaluated in early postoperative period, first postoperative month and third postoperative month (Table 2). There was no significant change in frequency of dysphagia between both groups in the early postoperative period, first postoperative month and third postoperative month. There were 5 female and 3 male patients (total: 8 ) in group A in the early postoperative period. Group B included 4 female and 3 male patients (total: 7) with dysphagia in the early postoperative period. There were no patients with dysphagia at the end of 3 months, which concludes that all patients with dysphagia in both groups had spontaneously recovered.

\section{Statistical Analysis}

Data were collected and analyzed by using IBM SPSS Statistics Version 25. Normality analysis were performed by using Kolmogorov-Smirnov test, Shapiro-Wilk test, Histogram and Variance coefficient. Related groups were compared by using Wilcoxon test. $\mathrm{P}<0.05$ was considered significant (Table 3 ).

Data is analyzed by using IBM SPSS Statistics version 25. Homogenicity of variants was evaluated with Levene's test for Equality of Variances. Normality analysis were performed by using Shapiro-Wilk test, Shapiro-Wilk test, Histogram and Variance coefficient. Comparison of independent groups was performed with Mann-Whitney U non-parametric test. $\mathrm{P}<0.05$ was considered significant.

\section{DISCUSSION}

Dysphagia is the most common postoperative complaint of anterior spinal surgery, and is usually transient. It most frequently starts in the immediate postoperative period; however, it can also develop 1 month after the surgery. Dysphagia incidence has a wide spectrum in the first postoperative week, varying between $1 \%$ and $79 \%$. Moderate and long-term postoperative (1 week to 6 weeks) rates of incidence are $28 \%$ to $57 \%$. Meta-analysis and case reports indicated higher rates ${ }^{(5)}$. The meta-analysis by Bazaz et al. ${ }^{(4)}$ reported a postoperative dysphagia incidence of max. $71 \%$ within the first two postoperative weeks; however, it decreases in the following months. Nonetheless, $12 \%$ and $14 \%$ of patients may encounter permanent dysphagia 1 year after the surgery.

Our patients with dysphagia in the beginning described gradually improving condition within 2 months, and all patients denied dysphagia by the end of third month.

The cause of postoperative dysphagia is not clearly uncovered. Various causes are suggested. These should be questioned in order. Peroperative retraction may cause edema. When vessel and nerve packets are separated and prevertebral fascia is reached, the retractors used for exposing the surgical site work by medially retracting the esophagus and trachea. Even when the surgery lasts short, the esophageal edema may cause dysphagia $a^{(6,7)}$. When retractors are evaluated, the commonly Cloward ${ }^{(9)}$ retractors may lead to edema with this mechanism. Similarly, the Casper ${ }^{(10)}$ et al. retractors, designed to maintain a better sight of the area, which are still commonly used, push the medial wall, probably causing edema in the same fashion ${ }^{(8-10)}$. The Ozer ${ }^{(11)}$ retractor used in our hospital does not cause a continuous compression, resulting in less edema and is more suitable for use. In this respect, it is less traumatic and useful in anterior cervical surgery.

Arthritic changes, anterior cervical osteophytic formations secondary to diffuse idiopathic skeletal hyper-osteosis or anterior cervical hyper-osteophytosis, mechanical compression on esophagus or inflammation causing fibrosis and adhesions may lead to dysphagia. The removal of anterior osteophytes during surgery highly reduces dysphagia incidence ${ }^{(12,13)}$. Two prospective comparative and one prospective study has investigated whether the plates used in anterior cervical discectomy cause dysphagia with similar mechanisms ${ }^{(14-16)}$. A non-randomized prospective study reported that thicker plates are significant associated with dysphagia ${ }^{(14)}$. The other study revealed smaller dysphagia incidence with non-compressive

Table 1. Bazaz-Yoo scoring in patients with dyaphagia ${ }^{(4,5)}$

Dysphagia episode (as stated by the patient)

\begin{tabular}{lll}
\hline Dysphagia & Liquid & Solid \\
\hline None & None & None \\
\hline Mild & None & Mild \\
\hline Moderate & None/mild & Intermittently (with some foods like meat or bread) \\
\hline Severe & Yes & Frequent (most of solid foods) \\
\hline
\end{tabular}


Table 2. Patients and groups enrolled in the study with their dysphagia scores

\begin{tabular}{|c|c|c|c|c|c|c|c|c|}
\hline Groups & Patient no & Gender & $\begin{array}{l}\text { Dyspagia after } \\
\text { surgery? }\end{array}$ & How long & Score & $\begin{array}{l}\text { Dysphagia } 3 \\
\text { months later? }\end{array}$ & $\begin{array}{l}\text { Eresion } \\
\text { barrier? }\end{array}$ & Operation \\
\hline & 1 & $\mathrm{~F}$ & $(-)$ & & & $(-)$ & No & Bladed peek cage \\
\hline & 2 & $\mathrm{~F}$ & $(+)$ & 1 Month & 1 & $(-)$ & Yes & Bladed peek cage \\
\hline & 3 & $\mathrm{~F}$ & $(+)$ & 2 Month & 2 & $(-)$ & Yes & Bladed peek cage \\
\hline & 4 & $M$ & $(-)$ & & & $(-)$ & No & Bladed peek cage \\
\hline & 5 & M & $(-)$ & & & $(-)$ & No & Bladed peek cage \\
\hline & 6 & $\mathrm{~F}$ & $(-)$ & & & $(-)$ & No & Bladed peek cage \\
\hline & 7 & $\mathrm{~F}$ & $(+)$ & 3 Month & 3 & $(-)$ & No & Bladed peek cage \\
\hline & 8 & M & $(+)$ & 4 Month & 4 & $(-)$ & Yes & Bladed peek cage \\
\hline & 9 & M & $(-)$ & & & $(-)$ & Yes & Bladed peek cage \\
\hline \multirow[t]{20}{*}{ Group A } & 10 & $M$ & $(-)$ & & & $(-)$ & Yes & Bladed peek cage \\
\hline & 11 & $M$ & $(-)$ & & & $(-)$ & No & Bladed peek cage \\
\hline & 12 & $\mathrm{~F}$ & $(+)$ & 3 Days & 1 & $(-)$ & No & Bladed peek cage \\
\hline & 13 & $\mathrm{~F}$ & $(+)$ & 2 Weeks & 4 & $(-)$ & Yes & Bladed peek cage \\
\hline & 14 & $M$ & $(+)$ & 1 Month & 3 & $(-)$ & No & Bladed peek cage \\
\hline & 15 & $\mathrm{~F}$ & $(-)$ & & & $(-)$ & No & Bladed peek cage \\
\hline & 16 & M & $(+)$ & 2 Weeks & 3 & $(-)$ & No & Bladed peek cage \\
\hline & 17 & $\mathrm{~F}$ & $(-)$ & & & $(-)$ & Yes & Bladed peek cage \\
\hline & 18 & $\mathrm{~F}$ & $(-)$ & & & $(-)$ & No & Bladed peek cage \\
\hline & 19 & $M$ & $(-)$ & & & $(-)$ & No & Bladed peek cage \\
\hline & 20 & $M$ & $(-)$ & & & $(-)$ & No & Bladed peek cage \\
\hline & 1 & M & $(-)$ & & & $(-)$ & Yes & ACDF prosthesis \\
\hline & 2 & $\mathrm{~F}$ & $(+)$ & 1 Week & 4 & $(-)$ & No & ACDF prosthesis \\
\hline & 3 & $M$ & $(-)$ & & & $(-)$ & No & ACDF prosthesis \\
\hline & 4 & $M$ & $(-)$ & & & $(-)$ & No & ACDF prosthesis \\
\hline & 5 & $M$ & $(+)$ & 2 Weeks & 4 & $(-)$ & No & ACDF prosthesis \\
\hline & 6 & $\mathrm{~F}$ & $(-)$ & & & $(-)$ & No & ACDF prosthesis \\
\hline & 7 & M & $(+)$ & 2 Weeks & 2 & $(-)$ & Yes & ACDF prosthesis \\
\hline & 8 & $M$ & $(+)$ & 6 Month & 2 & $(-)$ & No & ACDF prosthesis \\
\hline & 9 & M & $(-)$ & & & $(-)$ & No & ACDF prosthesis \\
\hline \multirow[t]{11}{*}{ Group B } & 10 & $\mathrm{~F}$ & $(-)$ & & & $(-)$ & No & ACDF prosthesis \\
\hline & 11 & $\mathrm{~F}$ & $(-)$ & & & $(-)$ & No & ACDF prosthesis \\
\hline & 12 & M & $(-)$ & & & $(-)$ & Yes & ACDF prosthesis \\
\hline & 13 & $\mathrm{~F}$ & $(+)$ & 3 Weeks & 4 & $(-)$ & Yes & ACDF prosthesis \\
\hline & 14 & $\mathrm{~F}$ & $(+)$ & 1 Week & 2 & $(-)$ & No & ACDF prosthesis \\
\hline & 15 & M & $(-)$ & & & $(-)$ & No & ACDF prosthesis \\
\hline & 16 & $\mathrm{~F}$ & $(+)$ & 3 Days & 3 & $(-)$ & Yes & ACDF prosthesis \\
\hline & 17 & $\mathrm{~F}$ & $(-)$ & & & $(-)$ & No & ACDF prosthesis \\
\hline & 18 & $\mathrm{~F}$ & $(-)$ & & & $(-)$ & No & ACDF prosthesis \\
\hline & 19 & $\mathrm{~F}$ & $(-)$ & & & $(-)$ & Yes & ACDF prosthesis \\
\hline & 20 & M & $(-)$ & & & $(-)$ & Yes & ACDF prosthesis \\
\hline
\end{tabular}

M: Male, F: Female, ACDF: Anterior cervical discectomy and fusion 
Table 3. Statistic results for both groups

\begin{tabular}{ll}
\hline \multicolumn{1}{l}{ Test statistics } & \\
\hline & Dysphagia score \\
\hline Mann-Whitney U & 195,000 \\
\hline Wilcoxon W & 405,000 \\
\hline$Z$ & -0.156 \\
\hline Asymp. Sig. (2-tailed) & 0.876 \\
\hline Exact Sig. [2*(1-tailed Sig.)] & 0.904 \\
\hline a. Grouping Variable: Group & \\
\hline b. Not corrected for ties. \\
\hline There is no significant difference between both groups $(\mathrm{p}>0.05)$
\end{tabular}

zero-profile plates ${ }^{(16)}$. No plate is used in our patient series, only stand-alone cage is utilized. This may have led to better outcome.

The use of bone morphogenic protein has been proposed to cause dysphagia by inflammation. Two retrospective and one prospective non-randomized controlled study investigated the risk regarding use of rhBMP-2 for postoperative dysphagia. rhBMP-2 has been suggested to cause increase in esophageal motility and dysphagia by inducing inflammation and edema in esophagus and surrounding soft tissues ${ }^{(17-20)}$. In this respect, rhBMP-2 use has the potential to cause more severe consequences like edema, airway stenosis or nerve entrapment and United States Food \& Drug Administration has warned against its use in anterior cervical surgery. rh-BMP-2 is not used in any of our patients, and according to operative reports, the osteophytes have been placed inside the cage by pressing and use of autograft. This way, the induction of inflammatory events by rhBMP-2 was avoided, leading to better outcomes.

Prospective cohort studies of Lee et al. ${ }^{(21)}$ and Bazaz et al.(4) reported that gender is an important risk factor when they identified women with complaint of dysphagia described 6 months after the surgery. On the contrary, a smaller prospective comparative study by Rihn et al. (22) and a retrospective study by Riley et al. ${ }^{(23)}$ did not reveal gender as an important risk factor. Gender was also not an important risk factor in our study.

Graft loss, infection and hematoma are important causes of dysphagia; however, they are not included in this study.

Covering the exposed surfaces during spinal decompression surgery, adhesion barriers constitute a transient, protective physical barrier by isolating the exposed nerve fibers and dura mater from surrounding tissue. They prevent entrapment of nerve fibers by stopping the development of adhesions with epidural fibrosis. They also may limit peroperative exposure of nerve fibers and main dura mater to biochemical irritants. However, no difference was identified with or without using adhesion barriers in early or late postoperative period, we do not consider them useful, especially in single level discectomy.

\section{CONCLUSION}

As a result, autograft use with cage leads to successful outcomes in single level anterior cervical discectomy. Use of adhesion barrier has no positive or negative effects. The early postoperative dysphagia gradually improves and lasts for 3 months, and disappears by the end of 3 months.

\section{Ethics}

Ethics Committee Approval: Ethical approval was obtained from Üsküdar University Chair of Non-Interventional Studies Ethnics Committee with no: 61351342/AUGUST 2021-01.

Informed Consent: Retrospective study.

Peer-review: Internally peer-reviewed.

Financial Disclosure: The author declared that this study received no financial support.

\section{REFERENCES}

1. Yue WM, Brodner W, Highland TR. Persistent swallowing and voice problems after anterior cervical discectomy and fusion with allograft and plating: a 5- to 11-year follow-up study. Eur Spine J. 2005; 14:677-82.

2. Mendoza-Lattes S, Clifford K, Bartelt R, Stewart J, Clark CR, Boezaart AP. Dysphagia following anterior cervical arthrodesis is associated with continuous, strong retraction of the esophagus. J Bone Joint Surg Am. 2008;90:256-63.

3. American Speech-Language-Hearing Association. Swallowing disorders (dysphagia) in adults. 2013. Last Accessed Date: 15.01.2013. Available from: http://www.asha.org/public/speech/swallowing/ Swallowing-Disorders-in-Adults/.

4. Bazaz R, Lee MJ, Yoo JU. Incidence of dysphagia after anterior cervical spine surgery: a prospective study. Spine (Phila Pa 1976). 2002;27:2453-8.

5. Anderson KK, Arnold PM. Oropharyngeal dysphagia after anterior cervical spine surgery: a review. Global Spine J. 2013;3:273-86.

6. Kang SH, Kim DK, Seo KM, Kim KT, Kim YB. Multi-level spinal fusion and postoperative prevertebral thickness increase the risk of dysphagia after anterior cervical spine surgery. J Clinical Neurosci. 2011;18:1369-73.

7. Kepler CK, Rihn JA, Bennett JD, Anderson DG, Vaccaro AR, Albert TJ, et al. Dysphagia and soft-tissue swelling after anterior cervical surgery: a radiographic analysis. Spine J. 2012;12:639-44.

8. Cloward RB. The anterior approach for removal of ruptured cervical disks. J Neurosurg. 1958;15:602-17.

9. Cloward RB. New method of diagnos's and treatment of cervical disc disease. Clin Neurosurg. 1962;8:93-132.

10. Caspar W, Barbier DD, Klara PM. Anterior cervical fusion and Caspar plate stabilization for cervical trauma. Neurosurgery. 1989;25:491-502.

11. Ozer AF. The latest design of Ozer cervical retractor. Neurol Res. 2008;30:695-6.

12. Ozgursoy OB, Salassa JR, Reimer R, Wharen RE, Deen HG. Anterior cervical osteophyte dysphagia: manofluorographic and functional outcomes after surgery. Head Neck. 2010;32:588-93.

13. Urrutia J, Bono CM. Long-term results of surgical treatment of dysphagia secondary to cervical diffuse idiopathic skeletal hyperostosis. Spine J. 2009;9:13-7.

14. Chin KR, Eiszner JR, Adams SB Jr. Role of plate thickness as a cause of dysphagia after anterior cervical fusion. Spine (Phila Pa 1976). 2007;32:2585-90. 
turkishspine

15. Lee MJ, Bazaz R, Furey CG, Yoo J. Influence of anterior cervical plate design on Dysphagia: a 2-year prospective longitudinal follow-up study. J Spinal Disord Tech. 2005;18:406-9.

16. Scholz M, Schnake KJ, Pingel A, Hoffmann R, Kandziora F. A new zeroprofile implant for stand-alone anterior cervical interbody fusion. Clin Orthop Relat Res. 2011;469:666-73.

17. Buttermann GR. Prospective nonrandomized comparison of an allograft with bone morphogenic protein versus an iliac-crest autograft in anterior cervical discectomy and fusion. Spine J. 2008;8:426-35.

18. Shields LB, Raque GH, Glassman SD, Campbell M, Vitaz T, Harpring J, et al. Adverse effects associated with high-dose recombinant human bone morphogenetic protein-2 use in anterior cervical spine fusion. Spine (Phila Pa 1976). 2006;31:542-7.

19. Vaidya R, Carp J, Sethi A, Bartol S, Craig J, Les CM. Complications of anterior cervical discectomy and fusion using recombinant human bone morphogenetic protein-2. Eur Spine J. 2007;16:1257-65.
20. Siska PA, Ponnappan RK, Hohl JB, Lee JY, Kang JD, Donaldson WF 3rd. Dysphagia after anterior cervical spine surgery: a prospective study using the swallowing-quality of life questionnaire and analysis of patient comorbidities. Spine (Phila Pa 1976). 2011;36:1387-91.

21. Lee MJ, Bazaz R, Furey CG, Yoo J. Risk factors for dysphagia after anterior cervical spine surgery: a two-year prospective cohort study. Spine J. 2007;7:141-7.

22. Rihn JA, Kane J, Albert TJ, Vaccaro AR, Hilibrand AS. What is the incidence and severity of dysphagia after anterior cervical surgery? Clin Orthop Relat Res. 2011;469:658-65.

23. Riley LH 3rd, Skolasky RL, Albert TJ, Vaccaro AR, Heller JG. Dysphagia after anterior cervical decompression and fusion: prevalence and risk factors from a longitudinal cohort study. Spine (Phila Pa 1976). 2005;15:2564-9. 